\title{
A Epistemologia da Química e a Estrutura e Logica dos seus Discursos
}

\author{
DUARTE DA COSTA PEREIRA *
}

Procura-se caracterizar a epistemologia da Química, analisando-se a estrutura $e$ uniformidade do discurso químico. Faz-se seguidamente uma tentativa para estabelecer a estrutura da Química, combinando as suas componentes teórica e experimental. Finalmente procura explicar-se porque é que na unificação do discurso químico e na sua ligação com o discurso de outras disciplinas o conceito de energia é da maior importância, sendo inferidas algumas implicações para o curriculum provenientes desse facto.

\section{1- INTRODUÇÃO. IMPORTÂNCIA DO ESTUDO DA REPRESENTAÇÃO E ESTRUTURA DO CONHECIMENTO QUÍMICO}

As questões da estrutura do conhecimento químico, do seu desenvolvimento e representação e do seu uso e validação, têm sido postas, com grande prioridade, quer naturalmente, nos quadros da Epistemologia da Química e da Química Teórica, para a esclarecer, quer no domínio da própria Química, para lhe aumentar a eficiência, e ainda no panorama da investigação em Educação em Química, como resultado de um crescente interesse de certos sectores pelas teorias académicas da Educação [1].

Neste último aspecto e não obstante a dicotomia subjacente às posições de objectividade ("erklaren") e subjectividade ("verstehen") do conhecimento científico [2], dividirem profundamente a comunidade científica, tem havido um crescente interesse no estudo da estrutura e lógica da Química que tem conseguido co-habitar com o paradigma construtivista das concepções alternativas ${ }^{\perp}$, dominante na Educação científica e com as visões pósmodernas, mais ou menos iluministas que têm dominado o panorama da Filosofia Científica.
Para o estudo da representação do conhecimento científico - o discurso científico - têm sido utilizados vários processos, sendo as práticas mais comuns: o estabelecimento directo, pelos sujeitos, de um mapa, a análise de tarefas dando origem a uma relação hierárquica de aprendizagem e ainda a análise de protocolos de entrevistas "clínicas". Suscitou-se também um grande interesse pela análise do discurso químico [3, 4] para caracterizar didacticamente os textos ou ainda as estruturas cognitivas que lhes estão subjacentes [5]. O interesse do uso de tais estruturas é múltiplo:

- para caracterizar a Epistemologia da Química

- para caracterizar a Teoria da Química

- na investigação Química, para previsão

- para professores autores e planificadores curriculares, o de se obter uma melhor sequência da instrução

- para os alunos, o de facilitar a aprendizagem.

A estrutura formal da Química caracteriza-se pela existência de Ramos separados há já muito tempo e que foram objecto dum desenvolvimento conceptual desarticulado. Primeira a desenvolver-se com uma teoria própria de Mecanismos de Reaçcões, a Química Orgânica mantém termos e conceitos muito diferentes da Inorgânica, por exemplo. Este estado de coisas tende a manterse, pelo desenvolvimento exponencial a que tem estado submetida a Ciência [6], que torna impossível a aquisição do domínio de conhecimentos em mais do que um limitado campo de um Ramo.

No entanto as representações químicas essenciais continuam a ser os Símbolos, as Fórmulas e as Equações havendo uma certa estrutura e uniformidade do discurso químico que é objectivo essencial deste artigo caracterizar (ponto 3) o que se faz logo após a caracterização da epistemologia da Química (ponto 2). Em seguida faz-se uma tentativa de esta- belecer a estrutura da Química (ponto 4) combinando as suas componentes experimentais e teóricas. Finalmente na unificação do discurso químico e na ligação com as outras disciplinas, o conceito de Energia desempenha um papel importantíssimo.

Ao longo do texto perpassam comentários à adopção, previsível para um futuro mais ou menos remoto, de uma nova semiótica [7] (Costa Pereira, 1991a) que poderia libertar a Química do paradigma das ligações localizadas de Lewis tão adaptado ao processo de comunicação de "papel e lápis", em favor de um conjunto de sinais (fórmulas) suportado por um processo electrónico que exibissem dados mais completos sobre os átomos ligados, as características das ligações e as reactividades.

\section{2 - CARACTERIZAÇÃO DA EPISTEMOLOGIA DA QUÍMICA}

A complexidade contemporânea da Ciência, que a Química naturalmente compartilha, é, do ponto de vista epistemológico, essencialmente proveniente de quatro factores:

- Em primeiro lugar, de uma indecisão entre o determinismo, ilustrado nas equaçōes diferenciais que caracterizaram a Revolução Newtoniana e que rapidamente se expandiram a outros campos (incluindo a Química), causando a euforia científica do Século XIX e o indeterminismo, quer de origem estatística que se veio a consolidar no fim do mesmo Século com a Teoria Cinética dos Gases e a Termodinâmica Estatística, bem como o de origem essencial devido ao carácter aleatório dos fenómenos à escala atómica e introduzido pela Revolução Quântica. A Química pelas suas bases lógicas, e certos campos seus, como o da Cinética Química especialmente, são, como veremos exemplos típicos desse carácter híbrido.

- Em segundo lugar, do facto de a Ciência actual não ter digerido 
ainda os aspectos complexos provenientes das não linearidades e, especialmente patentes na Química no comportamento dos sistemas longe do equilíbrio (teoria do caos), mantendo pelo contrário as tendências simplificadoras e reducionistas que fizeram o seu sucesso desde o tempo de Descartes, mas que se arriscam agora, se não houver uma revolução científica (no sentido Kuhniano), a diminuir-lhe o valor preditivo.

- Em terceiro lugar, porque o actual paradigma científico também é extremamente fragmentado (ou se se quiser, coexistem vários paradigmas) pelas dificuldades que tem havido para unificar as várias forças e os seus campos: as gravíticas, as electromagnéticas, as nucleares fracas e as nucleares fortes. Esta circunstância não afecta especialmente a Química, já que (se excluirmos a Química Nuclear) as únicas forças relevantes são as electromagnéticas mas, o que é certo é que o mais que se progrediu neste domínio foi na unificação das forças electromagnéticas e fracas no chamado campo electro-fraco, tendo sido mal sucedidas todas as tentativas de aproximação da relatividade e da teoria quântica (ilustradas no insucesso, até a data, duma teoria quântica da gravitação). A fragmentação (ou, se quiser, o desdobramento) do paradigma Químico aparece, no entanto, por outras razões adiante expostas (desenvolvimento em paralelo da Teoria da Ligação de Valência e da Teoria das Orbitais Moleculares).

- Em quarto lugar, por não existir uniformidade de interpretação para importantes ramos da Ciência como a Mecânica Quântica (facto ilustrado pelo diálogo entre Bohr e Einstein, embora a versão não determinista seja actualmente preponderante).

São várias as peculiaridades metodológicas da Química, entre as quais avulta a dupla focagem no microscópico e no macroscópico, que pode originar o que já foi referido como esquizofrenia do Químico. Outra destas peculiaridades é a foca- gem na quantidade de substância e não na massa como grandeza extensiva de referência que é, até certo ponto, uma consequência lógica da primeira opção. Pode também referir-se a incoerência de conceitos nos vários ramos proveniente do seu desenvolvimento separado, condicionado pelo actual gigantismo da Química e a que podem juntar-se questões menores mas bem características, tais como a preferência pela utilização de certas funções de estado, como a entalpia $(\mathrm{H})$ e a função de Gibbs (G) (permitam-me que me refira a ela pelo seu nome mais rico de Energia livre de Gibbs), em vez da energia interna (U) e da função de Helmoltz(F) mais usadas na Física. Quanto ao objecto do seu estudo, excluindo uma parte que se disputa entre a Física e Química (Química Nuclear e Física Atómica), poder-seá dizer, com toda a ambiguidade que esta afirmação contém, que a Química trata das mudanças materiais, a não muito altas temperaturas (senão temos a Física de Plasmas), em que são substancialmente afectados os electrões mais energéticos. O uso de unidades especiais, como a caloria, chegou a caracterizar a Química, que também dispunha de convenções próprias quanto aos sinais da variação da energia mas, quer num caso quer no outro, essas práticas não são mais toleradas pela comunidade científica.

Por outro lado, embora as bases históricas da Química sejam muito diversificadas, pode considerar-se que, de todas as Ciências da Nature$\mathrm{za}$, foi aquela que se processou com mais continuidade, isto é, com menores rupturas epistemológicas (Bachelard) ou revoluções (Kuhn). Assim, passou-se com razoável continuidade da alquimia e do flogisto para a teoria materialista de Lavoisier e atomista de Dalton e, como veremos (vide 3.1), com artifícios como a teoria de Ligação de Valência, até a adaptação à Mecânica Quântica foi suave. Durante o Séc. passado, no entanto, muitos químicos ilustres pensavam que as fórmulas químicas tinham apenas um valor heurístico e outros, como Ostwald, recusavam-se a admitir os átomos.

Com efeito, depois do sucesso da aplicação da Estatística a certos problemas que teve como resultado o estabelecimento da Teoria Cinética dos Gases e da Termodinâmica Estatística, ${ }^{2}$ e principalmente depois da explicação por Einstein do Movimento Browniano3, os átomos foram admitidos sem reservas na Ciência e muito especialmente na Química. Isto a ponto de se poder dizer que o aspecto mais importante que caracteriza a actual epistemologia da Química e a pressuposição dum sistema corpuscular [8], isto é que o comportamento dos sistemas pode ser explicado em termos do comportamento de outras entidades menores que o integram, ao passo que a Física continua essencialmente a admitir (epistemologicamente, claro!) a continuidade da matéria a que adicionou o conceito de aç̧ão a distância (formalizado pela noção de campo). Por alguma razão a base quantificadora da Química é a quantidade de substância, enquanto que a da Física e a massa!

Não obstante estas divergências e outras que adiante referiremos, há tendência em considerar a Química e a Física como pertencentes a um mesmo corpo de conhecimentos, designado por Ciências Físicas ${ }^{4}$. Uma sistematização de tais Ciências apontaria, segundo Bent [9] (1965), para o seguinte esquema:

\begin{tabular}{lccc}
\hline & Muito Pequeno & Moderado & Muito Grande \\
\hline Número de partículas & $\mathrm{MN}$ & & $\mathrm{ME}, \mathrm{Q}$ \\
Tamanhos das partículas & $\mathrm{MQ}, \mathrm{Q}$ & $\mathrm{MN}$ & Ast \\
Velocidade das partículas & $\mathrm{Est}$ & $\mathrm{MN}$ & Rel \\
\hline
\end{tabular}

$\mathrm{MN}=$ Mecânica Newtoniana $\quad \mathrm{ME}=$ Mecânica Estatística $\mathrm{MQ}=$ Mecånica Quåntica $\quad$ Ast $=$ Astronomia Clássica Est $=$ Estática $\quad$ Rel $=$ Relatividade

$\mathrm{Q}=$ Quimica 
Assim, a Química, como Ciência que estuda o comportamento de grandes conjuntos de partículas muito pequenas, fá-lo sobretudo com base na Mecânica Quântica (que estuda as partículas muito pequenas) e na Mecânica Estatística (que estuda os grandes conjuntos).

Estas raízes disciplinares híbridas tornam a abordagem da Química particularmente confusa, [10] já que são poucos os cursos superiores em que as duas componentes aparecem equilibradas, havendo, geralmente, uma tendência para privilegiar a componente Quântica em detrimento da componente Estatística, que ou não aparece ou aparece no fim do curso, cercada de um formalismo que torna a sua aplicação as situações do dia a dia difícil (como se tem provado com entrevistas feitas a licenciados [11, 12]. Acresce ainda o facto de, nos cursos superiores de Química, a Termodinâmica ser ainda muitas vezes abordada de forma exclusivamente clássica o que, podendo estar correcto formalmente, retira a capacidade desta Ciência servir de ponte entre o microscópico e o macroscópico, complicando ainda mais os modelos mentais [13] dos utentes da Química, que se vêem obrigados a usar modelos separados para a realidade macroscópica e para a sua interpretação microscópica.

Felizmente que, os aspectos quânticos e estatísticos são "separáveis", numa certa medida, permitindo, até certo ponto, a consideração em separado dos aspectos estruturais e dinâmicos da Química. Com efeito, à temperatura ambiente, o espaçamento dos níveis quânticos correspondente à energia associada com o movimento dos electrões, a chamada energia electrónica ${ }^{5}$, é muito grande comparativamente com a energia disponível, e a melhor maneira de se cumprir o inexorável $2^{\circ}$ Princípio da Termodinâmica é a de os electrões, como fermiões que são, não podendo ser descritos por uma mesma descrição quântica ${ }^{6}$, ocuparem as soluções (orbitais) menos energéticas ${ }^{7}$. constituindo as unidades básicas da estrutura da química: os átomos, moléculas ou cristais no seu estado fundamental. Para concretizar esta ideia, Bent [9] propōe um conceito de temperatura característica- $\mathrm{T}_{\mathrm{C}}{ }^{8}$ que seria a temperatura à qual o primeiro nível quântico excitado associado aos vários graus de liberdade (todos quantificados!) das moléculas (translação, rotação, vibração energia electrónica e energia nuclear) estaria significativamente preenchido. Essa temperatura seria dada por

$$
T_{c}=\varepsilon / k
$$

Em que

$$
\varepsilon=\mathbf{h}^{2} / \mathbf{m l}^{2}
$$

é o espaçamento entre níveis (hconstante de Planck, k-constante de Boltzmann, m-massa das entidades envolvidas, 1-comprimentos típicos ${ }^{9}$ associados aos movimentos). Substituindo por valores típicos é fácil, encontrar valores como: $10^{-17} \mathrm{~K}, 2 \mathrm{~K}$, $2000 \mathrm{~K}, 40000 \mathrm{~K}$ e $10^{11} \mathrm{~K}$ para as temperaturas características associadas a cada um daqueles movimentos, o que confirma plenamente a quase exclusividade do estado fundamental electrónico para as temperaturas moderadas da crosta terrestre (já o mesmo não será no Sol, nem no interior do nosso planeta!).

Esta ideia de separação dos aspectos quânticos e estatísticos da Química está na base da distinção de três tipos ou mesmo níveis (porque existe de facto uma hierarquia) distintos de discursos em Química [7] em que os objectos do discurso e os seus argumentos são bem diferenciados. Tal separação tem sido também muito usada no desenvolvimento curricular da Química em que geralmente se abordam separadamente os aspectos estruturais e os aspectos dinâmicos ${ }^{10}$. De facto, esta ideia da separação embora possa ser considerada uma ideia muito útil, não é inteiramente correcta, já que a Mecânica Quântica não se aplica só aos aspectos estruturais, pois também os aspectos reaccionais são em grande parte determinados pelas características das orbitais envolvidas (as HOMO e as LUMO ${ }^{11}$ ), calculadas por aplicação da Mecânica Quântica, como ainda, porque não só considerações de probabilidade ${ }^{12}$ explicam a ocorrência das reacções; por exemplo, uma reacção elementar ${ }^{13}$ de oxidação-redução é proibida, pelo princípio de exclusão de Pauli (princípio quântico), de envolver mais de dois electrões $^{14}$

\section{3 - OS NÍVEIS DA QUÍMICA E OS SEUS DISCURSOS}

O carácter complexo e as raízes híbridas ${ }^{15}$ da Química não impedem esta disciplina, de ter conceitos próprios (às vezes até indesejavelmente distintos de uns ramos da Química para outros) e linguagem e métodos bem característicos. Com base nas características que descrevemos de separabilidade dos aspectos quânticos e estatísticos e da dupla focagem no microscópico e no macroscópico podemos distinguir três tipos ou mesmo níveis de discurso na Química:

- (i) O nível estrutural ou quantum / electrónico, que trata da organização de electrões e núcleos em agregados (átomos, moléculas, iões, cristais, etc.)

- (ii) - O nível reaccional ou estatístico / molecular que trata da caracterização (tendência ou descrição detalhada) das reacções das entidades descritas no nível anterior

- (iii)-O nível macroscópico ou termodinâmico /clássico que trata da descrição macroscópica dos sistemas químicos e em particular das suas reacções (descritas microscopicamente no nível anterior).

Vamos, brevemente, considerar cada um destes níveis e procurar caracterizar os seus discursos.

\section{1 - 0 nível estrutural ou quantum / electrónico}

Numa perspectiva epistemológica corpuscular, que é como dissemos apanágio da Química, o nível mais 
básico do discurso desta ciência, se excluirmos a Química Nuclear da nossa apreciação, é o que considera as estruturas atómicas e pluri-atómicas com base no protagonismo dos electrões. A representação formal de todos os elementos desta linguagem tem por base os símbolos químicos (referentes aos átomos, a que numa tradição alquímica e Daltoniana se atribui existência independente) e as fórmulas químicas que representam os materiais, com mais ou menos informação (podem ir desde as simples fórmulas empíricas até às detalhadas fórmulas estereoquímicas e aplicar-se tanto a compostos moleculares como a estruturas gigantes). Nestas fórmulas, por vezes, explicitam-se alguns electrões (electrões de valência) geralmente associados aos pares (dupletos de Lewis) em ligações localizadas.

Este é o panorama geral do discurso estrutural químico cuja aparente simplicidade esconde muitas complicações. Com efeito, o papel dos átomos na explicação Química é decisivo, desde a introdução por Dalton em 1807 da Hipótese Atómica, a que se seguiram, 50 anos mais tarde, as primeiras noções duradouras de estrutura molecular com Couper, abrindo caminho para os trabalhos mais conhecidos de Kékulé, Van't Hoff e Le Bel que se sucederam nas duas décadas seguintes. Tais trabalhos impuseram o conceito de molécula como arranjo razoavelmente rígido e estável de átomos no espaço tri-dimensional, supondo-se a existência de ligações entre pares de átomos. O papel do átomo, no entanto, não deixa de ser paradoxal, pois, quase que ao mesmo tempo que era entronizado na Ciência para além de qualquer dúvida ${ }^{16}$, convencendo os mais cépticos, o conceito de átomo que há cerca de um século servia de base às mais interessantes teorias químicas e conceitos ainda hoje mantidos por esta ciência (valência, afinidade, fórmulas, actividade óptica, etc.), é quase imediatamente desvalorizado pela negação da sua essência, ou mesmo pela admissão da sua não atomicidade, isto é, pelo reconhecimento da sua divisibilidade, demonstrada por Thomson com a descoberta do electrão e modelada por Rutherford no átomo nuclear, após a experiência fundamental de Geiger e Marsden. Esta ideia é finalmente compatibilizada com os resultados experimentais dos espectros de riscas (para o átomo de Hidrogénio) por Bohr (1913) que vai buscar a ideia dos quanta usada pela primeira vez por Planck para a explicação da radiação do corpo negro (1900) e por Einstein na explicação do efeito fotoeléctrico (1905). É na vigência da teoria de Bohr que surge a ideia notável de responsabilizar os electrões pelas ligações estabelecidas entre os átomos e materializadas nos dupletos de Lewis que ainda hoje, diga-se o que se disser, constitui o cerne da teoria estrutural da Química, principalmente no importante ramo da Química Orgânica. Com efeito é com base nestas ideias tão simples, que dão um significado físico às noções já antigas de valência $e$ afinidade química (em termos de carga eléctrica e das forças e energias associadas), que se progride substancialmente, através do génio notável de um homem - Sir Christopher Ingold - na descrição dos mecanismos da Química Orgânica, que se racionalizam através de propriedades de electrões como o efeito indutivo ou do comportamento dos substractos relativamente aos electrões como a electrofilia e a nucleofilia. Ideias simples como a das repulsões de pares, mais tarde envolvendo a atenção de homens notáveis como Sidgwick, Powell, Nyholm e Gilespie, explicam também cabalmente, em muitos casos, a forma das moléculas simples.

As leis quânticas de Bohr são introduzidas de uma forma ad-hoc, como leis quânticas da natureza (não teorias quânticas) segundo uma tendência que levou a considerarem-se como intrinsecamente quantizadas as grandezas físicas que tinham sido objecto de leis de conservação no Séc. XIX. Será preciso o reconhecimento duma propriedade fundamental da matéria importante a este nível - a não comutatividade de certas observações incidindo sobre propriedades mecânicas- para despoletar os fundamentos racionais da moderna Mecânica Quântica. Como se sabe o desenvolvimento desta fez-se por duas vias que se baseiam em dois tipos de entidades matemáticas reconhecidamente não comutaveis: as matrizes e as posições e suas derivadas. A primeira, seguida por Heisenberg, leva à Mecânica das Matrizes enquanto que a segunda, seguida por Schrodinger leva à Mecânica Ondulatória.

Isto introduz naturalmente duas linguagens neste domínio, mas dá-se o caso de os primeiros Químicos, como Pauling, que tentam aplicar a Mecânica Quântica à solução dos problemas químicos, o fazerem exclusivamente na aproximação ondulatória. Se isto é bom por um lado por manter a uniformidade do discurso Químico, por outro afasta esta ciência da outra aproximação, que embora demonstradamente equivalente, serve de suporte à maior parte dos progressos da teoria quântica inicial, a ponto do efeito relativista do spin introduzido com toda a naturalidade na Mecânica das Matrizes por Dirac ${ }^{17}$, para eliminar a assimetria entre o tempo e as outras dimensões, aparecer um pouco excrescente no seio da química, como um quarto número quântico metido a martelo. ${ }^{18}$

O caminho que seguem os Químicos Quânticos, sempre dentro da Mecânica Ondulatória ${ }^{19}$, diverge quase desde o princípio.

Um primeiro grupo, baseado nas ideias de separação dos movimentos electrónicos e nucleares introduzida por Born e Oppenheimer, "importa" as ideias clássicas de estrutura molecular para a Mecânica Ondulatória dando origem à Teoria da Ligação de Valência (TLV). Assim, Pauling e Slater começam por tratar o problema de moléculas simples diatómicas (na esteira do que os físicos Heitler e London haviam feito para o ião $\mathrm{H}_{2}{ }^{+}$) e obtêm sucesso ${ }^{20}$. pelo menos para a molécula de $\mathrm{H}_{2}$, estendendo rapidamente o processo 
a moléculas mais complexas. A base dos cálculos era, em todos os casos, combinações lineares de funçōes de onda atómica ligadas ao mesmo centro atómico (base do conceito de hibridização que surge com perfeita naturalidade nesta teoria), falando-se em ressonância entre estruturas sempre que uma solução localizada não era suficiente para justificar as propriedades exibidas.

Um segundo grupo, de que faziam parte Hund, Lennard-Jones e Mulliken, formula uma teoria alternativa com base em combinações lineares de funções atómicas de diferentes centros atómicos (não necessariamente os ligados pelas teorias convencionais) e em que a ideia de localização e de dupletos localizados aparece apenas como um tipo de solução possível em certos sistemas. A normalidade está em funções policêntricas e como tal "deslocalizadas". É a Teoria das Orbitais Moleculares (TOM).

Perante perspectivas tão diferentes, só se pergunta: como foi possível construir uma Química estrutural coerente (com um discurso coerente) baseada na teoria Quântica?

Vejamos, primeiro, as razões que apontam para uma certa simplicidade e, depois, como resolver a complicação proveniente daquelas duas perspectivas.

Assim, como se disse já, relativamente às forças envolvidas na caracterização deste nível estruturalo nível estrutural químico - a situação é o mais simples possível: apenas são significativas as forças electromagnéticas, enquanto que nas situações estruturais macroscópicas (abordadas satisfatoriamente pela Física Clássica) são significativas as forças gravíticas e electromagnéticas e no núcleo se fazem sentir as forças nucleares fortes e fracas. A "pureza" do campo estruturante que a Química apresenta relativamente ao campo electromagnético, só tem paralelo com a Astronomia. para a qual só tem significado o campo gravítico ${ }^{21}$.

Quanto à estrutura do discurso estrutural químico, é habitual distinguirem-se dois subníveis, conforme haja um só núcleo central - estrutura atómica - ou vários - estrutura molecular ou gigante. Essa distinção não é essencial, tendo em vista a desvalorização, já referida, da noção de átomo e porque, principalmente, se nos basearmos na Teoria das Orbitais Moleculares, a diferença formal esvai-se, ao representarem-se todos os electrões em orbitais, não necessariamente "localizadas" em um ou dois átomos 22 . De qualquer maneira, tanto a TOM como a TLV aproveitam como elementos básicos as soluções centrais (atómicas), mais simples, que são as soluções para o átomo de hidrogénio, corrigidas duma forma mais ou menos exaustiva para a presença de mais electrões.

Seja como for, os sujeitos da descrição estrutural/quântica são os electrões (particularmente os electrões de valência), sendo os objectos as estruturas que se obtêm (átomos, moléculas, iões, cristais, etc.) e sendo a linguagem fornecida pela Mecânica Quântica, através do delicado e controverso conceito de ligação química (vide a polémica relativamente recente entre Ogilvie e Linus Pauling surgida no Journal of Chemical Education [14, 15] que seria o predicado da linguagem estrutural, exprimindo essencialmente a modificação relativamente à situação atómica (ideal e hipotética).

Este conceito tem que entenderse, para ter uma certa universalidade, não da forma convencional materializada no dupleto de Lewis cara aos Químicos, mas tão somente como um abaixamento da energia provocado pela solução "ligada", relativamente à solução não "ligada" 23 . Isto também porque tal descrição energética, é a única maneira de descrever as "ligações" que conduzem a estruturas gigantes (a iónica e a metálica). Assim, o conceito de energia ${ }^{24}$ que aparecia já de uma forma perfeitamente natural, caracterizando soluções estáveis da equação de Schrodinger num prolongamento do paradigma de Hamilton para a dinâmica ${ }^{25}$, soluções essas que determinavam as funções de base da ligação ou das orbitais moleculares, aparece também central na escolha destas funções ${ }^{26}$

As bases do discurso estrutural possível são, sem dúvida, os postulados da Mecânica Quântica (representação proposicional rigorosa) e as suas consequências imediatas (como o princípio de incerteza de Heisenberg e o princípio de exclusão de Pauli). Há também, em face da insolubilidade rigorosa de sistemas mais complexos do que o do átomo de hidrogénio, uma quantidade de regras aproximadas (representações proposicionais não rigorosas, com diferentes graus de aproximação) como os métodos ab-initio, os cálculos semi-empíricos, a teoria do campo do ligando, etc., e a um outro nível (semi-quantitativo), o princípio de enchimento (aufbau), a regra do octeto, a teoria da repulsão dos pares electrónicos, juntamente com representações analógicas (modelos do átomo, das moléculas, dos cristais iónicos, dos cristais metálicos, das densidades electrónicas, dos potenciais etc.). A profusão de representações e conceitos explicativos é tão grande que se pode dizer que a situação é confusa, sendo isto não tanto devido ao apego que Ogilvie [14] denuncia a conceitos (como as orbitais ou a hibridização que não são mais do que métodos de cálculo dentro duma aproximação), mas que a meu ver se deve principalmente à confusão no mesmo discurso de conceitos com origem na Teoria da Ligação de Valência e de outros com origem na Teoria das Orbitais Moleculares, prática que infelizmente é muito comum na explicação Química mesmo a nível de livros de texto conceituados (para não falar também nos argumentos circulares mencionados por Ogilvie). Com efeito, há conceitos como hibridização ou deslocalização que tendo "nascido" numa das teorias não são completamente "transportáveis" para a outra. Estamos assim em presença de dois "dialectos" cujos termos não são e não devem ser arbitrariamente intercambiáveis. Esta situação é infeliz até porque dá às pessoas de fora da dis- 
ciplina uma ideia da Química como uma Ciência conceptualmente fraca (como ainda não há muito tempo foi afirmado por René Tom [16], o "pai" da Teoria das Catástrofes), quando, de facto, o que existe é uma grande confusão quer de discursos, ou melhor de dialectos, a este como também, conforme veremos, a outros níveis!

A tendência didáctica actual consiste em fazer aparecer a ligação química, sempre que possível, na sua versão de Lewis, de dupleto electrónico localizado. Com o advento do computador tornou-se possível a exploração das estruturas químicas duma forma mais fundamental [17] e mais consentânea com a concepção dominante da Mecânica Quântica 27 (a da Escola de Copenhaga). Exemplos disso são os programas HyperChem (para compatíveis) e CAChe (para Macintosh). Eles são ainda muito caros e estão orientados nitidamente para o ensino superior, principalmente ao manterem em aberto muitas possibilidades de cálculo acessíveis através de menus. Versões simplificadas destes programas poderão vir a produzir uma revolução básica no discurso estrutural da Química, ou mesmo na Semiótica da Química. De facto, o químico de hoje tem, como instrumento fundamental de comunicação e relacionamento dos seus conhecimentos, a ideia de ligação química localizada, o chamado dupleto de Lewis. Tal ideia, como se sabe, não explica os casos todos, podendo falar-se da necessidade duma mudança de sistema de representação. É possível que, no futuro, esses quadros mnemónicos subjacentes ao conhecimento químico - as fórmulas - sejam substituídos por esquemas de ligação, rapidamente acessíveis por computador, contendo muito mais informação, como a carga, ordem de ligação, polarizabilidade, etc., capazes de ajudar a prever o comportamento reactivo dos compostos, até porque a Teoria das Orbitais Moleculares, em que se baseariam, é muito adequada à implementação em computadores. Diga-se que o advento duma tal revolução seria extremamente útil para a uniformização conceptual da Química feita certamente à custa duma Teoria de Ligação de Valência tornada obsoleta.

\section{2 - 0 nível reaccional ou estatístico / molecular}

Este nível relaciona-se com o anterior através de conceitos ainda de descrição electrónica, como os de estado de transição e os de HOMO e LUMO, para além de todos os parametros quânticos que são indicadores de reactividade (polarização, polarizabilidade, ordem de ligação, etc.).

O nível em si é caracterizado por descrições que têm como sujeito moléculas ou conjuntos de átomos ou iões e por objecto as reaç̧ões químicas, constituindo as frases desta linguagem ou proposições desta teoria aquilo a que bastante impropriamente (baseados numa analogia tosca com a matemática) designamos por equações químicas e que têm a este nível uma leitura de representação dos fenómenos elementares (isto é, uma leitura "molecular", contrastando com a leitura molar do próximo nível). Existem neste nível, como veremos adiante, dois tipos de linguagem diferente (não simples dialectos, como acontecia no nível anterior): uma, estocástica ${ }^{28}$, seguindo o paradigma estatístico iniciado no séc. passado por Maxwell a propósito da teoria cinética dos gases; e outra, determinista (embora, como veremos, contendo uma parcela estocástica) seguindo o "modelo" das equações diferenciais inaugurado por Newton na Dinâmica e que se estendeu ao estudo de quase todos os fenómenos dinâmicos (electricidade, acústica, etc.). De facto, ao contrário do que acontecia com os aspectos estruturais em que a dependência temporal se podia ignorar, neste nível descritivo tal não acontece; ela própria é essencial à descrição, de forma que há pelo menos dois tipos de discurso: um que apenas pretende descrever a tendência dos sistemas e outro que especificamente dá conta da dependência funcional das quantidades químicas em ordem ao tempo, ambos podendo ter o suporte de teorias muito diversas, como a teoria das colisões, ou a teoria do estado de transição. Em tais discursos está sempre presente uma propriedade chamada energia, qualquer coisa que se pode referir a um processo contabilístico que dá sempre o mesmo resultado (vide a alegoria dos cubos com que-magistralmente Feynman "capta" o conceito - cf. Leitura suplementar) e em que surge a entropia apenas como uma maneira de contabilizar de uma forma sumativa e não multiplicativa as probabilidades das situações encontradas.

O primeiro discurso - Termodinâmica Estatística - tem uma base perfeitamente estocástica (mas aqui o estocástico é de natureza estatística e não fundamental como na Mecânica Quântica) baseada na ideia de distribuição (de energia, velocidades, etc.), ocupando o factor de Boltzmman $\left(e^{-E / k T}\right)$ um papel central. Considerando o espaço de fases dos sistemas Químicos, tal discurso que apenas aponta tendências da evolução desses sistemas, leva à consideração de atractores para os sistemas químicos, sejam eles os atractores pontuais que conduzem ao equilíbrio químico convencional, os atractores circulares que conduzem às menos familiares reaçcões oscilantes ou ainda a atractores estranhos que conduzem ao Caos! As duas últimas situações, embora frequentes em ramos como a Bioquímica, pouco ou nada são estudadas em abordagens convencionais da Química, mas também nada justifica que esta situação se mantenha, com os modernos instrumentos para estudar sistemas complexos, como são os computadores.

O segundo tipo de discurso Cinética Química - descreve, em função do tempo, o comportamento das espécies químicas em presença, com expressões em que intervêm velocidades de reaçcões (derivadas em ordem ao tempo das concentra- 
ções de espécies químicas), expressões algébricas dessas ou doutras concentrações e um factor designado por velocidade específica que depende das condições das reaç̧ões, entre as quais a temperatura a que se dá. Tal tipo de discurso é de facto um discurso híbrido, pois é determinista, na medida em que usa equações diferenciais, e é estocástico na medida em que pressupõe uma distribuição de velocidades e energias de acordo com determinado modelo estatístico. Pode mesmo dizer-se a partir da expressão genérica da velocidade de uma reaç̧ão

$$
-d[R] / d t=k f([A],[B] \ldots)
$$

que há uma completa separabilidade dos dois aspectos e, portanto, das duas linguagens, a estocástica aplicando-se a k, onde sobressai a dependência da temperatura, e a determinística aplicando-se a f, onde sobressai a dependência explícita das concentrações e implícita do mecanismo das reacções. A gramática deste discurso é a dos mecanismos das reaç̧ões em que os aspectos quânticos detalhados (como as caracteristicas de simetria das HOMO e das LUMO) são conciliados com os aspectos estatísticos reaccionais. Determinista, na medida em que usa equações diferenciais, pode, em certos casos, como o de autocatálise ou catálise cruzada de reacções bioquímicas, conduzir a percursos complicados, com uma certa periodicidade e mesmo a situações caóticas - Caos determinístico - facilmente caracterizáveis através da não linearidade das equações diferenciais subjacentes. Também aqui o computador, como modelador dinâmico por excelência, através de ciclos sucessivos de iterações, pode ser um bom suporte para este discurso!

\section{3 - 0 nível macroscópico ou termodinâmico /clássico}

Este nível é caracterizado por descrições que têm como objecto porções macroscópicas de matéria, ditos sistemas termodinâmicos e como sujeitos, variáveis que lhes estão associadas, designadas por funções de estado e como linguagem, a Termodinâmica Clássica, que remonta ao tempo de Carnot. ${ }^{29}$ As frases desta linguagem ou proposições desta teoria são também designadas por equações químicas e têm a este nível uma leitura de representação dos fenómenos referida à unidade de quantidade de substância das espécies envolvidas com um coeficiente estequiométrico 1 na referida equação (isto é, uma leitura molar contrastando com a leitura "molecular" do nível anterior). A energia aqui aparece como uma das funções de estado, a Energia Interna, relacionada com fenómenos fronteira, tal como a produção de calor e trabalho, e a entropia como associada à irreversibilidade dos fenómenos.

Uma das mais espantosas descobertas da humanidade é a da sinergética, que se pode descrever como a possibilidade de sistemas extremamente complexos e vastos se deixarem descrever por um pequeno número de parâmetros. É dessa descrição que trata a termodinâmica clássica que constitui o último nível de descrição química. É importante salientar que existe uma perfeita correspondência entre os conceitos deste nível e os da termodinâmica estatística do nível anterior ${ }^{30}$, embora estes dois discursos tenham consistência própria e sejam formalmente independentes.

É a este nível que se fazem muitas das determinações energéticas experimentais que servem depois para racionalizar os discursos dos outros níveis. Das variáveis que se determinam a este nível devem salientar-se o $\Delta \mathrm{H}^{0}$ (variação de entalpia padrão), objecto da termoquímica e cuja determinação se faz experimentalmente com calorímetros, cuja generalização se pode fazer pela lei de Hess e que serve essencialmente para caracterizar as trocas de calor em reacções a pressão constante (como são a maior parte das reacções químicas) e também para efectuar correcções de outras funções ou quantidades como a energia livre ou as constantes de equilíbrio quando a temperatura não é a padrão.

$\mathrm{O}$ trio $\Delta \mathrm{G}^{0}$ (variação de energia livre de Gibs padrão), $\mathrm{E}^{0}$ (potencial electroquímico) e $\mathrm{K}$ (constante de equilíbrio) desempenha um papel especialmente importante na previsão das reacçōes químicas e considerações de estabilidade de compostos, constituíndo uma das principais informações existentes nas Tabelas Químicas. Sendo todas estas grandezas interconvertíveis através de fórmulas simples e sendo a primeira, como função de estado que é, manipulável pela lei de Hess (tal como a entalpia, embora aqui as variações com a temperatura sejam muito maiores e precisem de ser corrigidas) é portanto generalizável a outras reacções; $E^{0}$ tem a grande vantagem de poder ser determinado experimentalmente pela construção de pilhas adequadas e $\mathrm{K}$ conduz rapidamente aos cálculos estequiométricos relevantes.

\section{4 -A ESTRUTURA DA QUÍMICA E OS SEUS DISCURSOS}

A estrutura formal da Química foi imposta pela História e não é, de todo, lógica. De facto, não há nenhuma lógica em divisões tais como a Química Orgânica (porque realçar um elemento?) ou QuímicaFísica (não será toda a Química, Física?).

Racionalmente, a estrutura da Química deveria ser determinada pela sua estrutura teórica (Mecânica Quântica e Mecânica Estatística - ver 2), os seus níveis teóricos, os seus discursos (ver 3) e os seus métodos de validação experimental ou de refutação (o último caso aplicandose se seguir uma aproximação Popperiana da Ciência). A Química aparece de facto como um corpo teórico de conhecimentos apoiado na Mecânica Quântica e Mecânica Estatística tendo ligado um corpo experimental constituído não só por práticas observacionais mas também e acima de tudo por regras que ajudam a interpretar os resultados. 
Estas extensões empíricas são, de facto, "janelas" químicas sobre o Mundo que se organizam em ramos e que tem arquitecturas peculiares implicando não apenas os métodos observacionais e experimentais, mas acima de tudo um enquadramento para interpretar as observações. O resultado é aquilo a que correntemente se chama discurso experimental e que se diferencia formalmente dos discursos teóricos tratados em 3.

Um dos mais importantes problemas em epistemologia é o de estabelecer se uma completa correspondência, ou pelo menos correlação, é possível entre as duas linguagens. Embora não tenhamos veleidades de resolver duma forma completa esse importante problema, é possível contribuir para a sua resolução ao indicar os mais importantes destes ramos experimentais e tentar correlacionálos com alguns dos discursos teóricos:

- (i) - Métodos físicos para determinar estruturas, os métodos espectroscópicos, quer os baseados na interação de radiacões com a matéria (difracção de raios $\mathrm{X}$ ou difracção electrónica) quer os baseados na interacção de campos com a matéria (RMN ou RPE); claramente relacionados com o nível reaccional $\left(1^{\circ}\right)$ do discurso teórico da Química.

- (ii) - Química analítica convencional qualitativa, quantitativa ou instrumental, também relacionada com o $1^{\circ}$ nível

- (iii) - Investigação empírica directa sobre as expressões de velocidade, relacionadas com o $2^{\circ}$ nível global.

- (iv) - Investigação sobre mecanismos das reacções, relacionadas com a componente determinística do $2^{\circ}$ nível, essencialmente especulativa e recorrendo ao suporte de (i), (ii) ou ambos, para confirmar estruturas de intermediários.

- (v) - Termoquímica, relacionada com o $3^{\circ}$ nível e indirectamente com a termodinâmica estatística, tendo por objectivo principal o determinar entalpias de formação de compostos $\left(\Delta \mathrm{H}^{0} \mathrm{f}\right)$ com as quais se podem determinar as entalpias de todas as reaç̧ões através da lei de Hess.

-(vi) - Electroquímica também relacionada com o $3^{\circ}$ nível e indirectamente com a estatística termodinâmica, tendo por objectivo principal o determinar os potenciais electroquímicos $\left(\mathrm{E}^{0}\right)$, facilmente relacionáveis com as constantes de equilíbrio e com a energia livre de Gibbs.

\section{5 - A ENERGIA COMO CONCEITO INTEGRADOR DA QUÍMICA E ARTICULADOR DA QUÍMICA COM AS OUTRAS CIÊNCIAS}

Na Química, conforme vimos em 3.1, no nível estrutural ou quantum / electrónico a energia aparece de uma forma perfeitamente natural, caracterizando soluções estáveis da Equação de Schrodinger num prolongamento do paradigma de Hamilton para a dinâmica e que pela primeira vez introduziu, de uma forma coerente o conceito de energia ${ }^{31}$. Temos também [18] vários conceitos energéticos utilizados no discurso estrutural da Química que são uma série de conceitos especificamente atribuíveis aos movimentos a nível molecular, especialmente os electrónicos (atribuíveis aos electrões) mas que se podem definir também a nível macroscópico pelo conhecido artifício molar. Temos entre outros: energia de ionização, afinidade electrónica, energias das orbitais, etc.

No nível reaccional ou estatístico / molecular está também sempre presente uma propriedade chamada energia; qualquer coisa que se pode referir a um processo contabilístico que dá sempre o mesmo resultado. Como processos energéticos utilizados no discurso reaccional da Química temos [18]: cinética molecular, condutibilidade, quimioluminescência e probabilidade (entropia).

Finalmente, no nível macroscópico ou termodinâmico /clássico a energia aparece [18] como interconversões e transferências de energia, e ainda no significado molar da dispersão e degradação da energia e ainda da energia de activação.
O conceito de energia é, portanto, um denominador comum [18, 20] de todos os discursos da Química. Trata-se, no entanto, de um conceito teórico, que aparece essencialmente como a quantidade que é conservada em qualquer transformação $\left(1^{\circ}\right.$ princípio-vide a alegoria de Feynman na leitura complementar) e que interage com a matéria segundo leis probabilísticas ( $2^{\circ}$ princípio) e para o qual todas as tentativas feitas [21] para a aplicação de um modelo operacional $^{32}$, falham, falhando também as tentativas de usar um modelo de dupla linguagem (teórica e observacional) [22]. Não admira pois, que não só os alunos apresentem grandes dificuldades como também, e principalmente, os próprios professores não se sintam à vontade no tópico. Estudos recentes em que foram entrevistados 11 professores de Física e Química, revelaram que só I tinha um conceito teórico correcto desta grandeza! Com efeito as concepções alternativas sobre este tópico proliferam e estendem-se a tópicos afins como o calor ${ }^{33}$.

De qualquer modo, como vimos, a Química não é só teórica, mas também experimental ${ }^{34}$ sendo de incentivar um equilíbrio razoável entre o empirismo e o racionalismo já advogado por Bacon [23] e muito enfatizado por Bachelard [24] e mais recentemente por Wittgenstein [25]. $\mathrm{Na}$ Química experimental há pelo menos três "janelas", ou melhor, enquadramentos lógicos para interpretar os resultados experimentais que usam o conceito de energia: os métodos espectroscópicos servindo especialmente o nível estrutural; a Termoquímica (que determina a entalpia $\Delta \mathrm{H}$ ) e a Electroquímica (que dá os valores dos potenciais electroquímicos), métodos que servem especialmente os níveis reaccionais. Todos estes métodos usam explicitamente o conceito de Energia embora, como dissemos, tenha sido impossível correlacionar completamente esta linguagem observacional com a linguagem teórica.

Por outro lado, o paradigma actualmente prevalecente em Educa- 
ção Científica - o das concepções alternativas [26] - tem revelado grandes dificuldades e principalmente falta de permanência das fórmulações da Física baseadas numa aç̧ão a distância, muito particularmente da Mecânica Newtoniana [27], baseada no conceito de força. Este é aparentemente mais simples que o conceito de energia que na formulação Hamiltoniana (posterior, historicamente) toma o lugar de conceito central, mas tal simplicidade é, de facto, aparente por ser simplesmente derivada de concepções alternativas $^{35}$, nada tendo a ver com a concepção Newtoniana de força. De facto, sendo tanto força como energia conceitos extremamente difíceis porque teóricos, eles fundamentam duas linguagens, rigorosamente equivalentes no que diz respeito a Mecânica Clássica [28]. Para saber qual das aproximações deve prevalecer por critérios didácticos é fundamental afirmar que os conceitos não devem ser julgados isoladamente, como uma certa formulação da teoria das concepções alternativas inspirada na Pedagogia do Não de Bachelard pretende [29], mas devem ser julgados pela compatibilidade com as estruturas de acolhimento com que entram em interacção [30], numa palavra, pela adequação da linguagem conceptual à estrutura mental do aprendiz. Desde logo sendo a energia um fenómeno local, não envolvendo acçōes à distância, o seu tratamento é operacionalmente menos complexo e sendo uma noção escalar, elimina mesmo a necessidade duma formulação vectorial da dinâmica (restringindo-a à cinemática). Por outro lado, o conceito de energia adapta-se também muito melhor à termodinâmica nas suas versões clássica (a que a força não se adapta) ou estatística (em que o calor se pode obter como soma dos trabalhos microscópicos não orientados...). Também a noção de campo resulta muito bem em todos os ramos da Física, associada, muitas vezes, a grandezas vectoriais (como o próprio campo eléctrico e magnético), mas tendo sempre subjacente o conceito escalar e local de energia. Finalmente não é demais lembrar que a Teoria da Relatividade ao promover a equivalência entre massa e energia e a Mecânica Quântica ao basear (na formulação de Schrodinger) os seus resultados numa adaptação das equações de Hamilton (precisamente aquelas que introduziram o conceito de energia na Física!) não fazem mais que reforçar a centralidade e a importância deste conceito nas Ciências Físicas. Fora destas, o conceito impõe-se também na Biologia, onde a Bioenergética é um ramo cada vez mais importante, e em áreas como a teoria da informação, onde conceitos relacionados com a energia, como a entropia, desempenham um papel fundamental.

Sendo assim, a linguagem centrada na energia impõe-se, em todas as Ciências. Permitam-me que lançe um apelo aos responsáveis pelo desenvolvimento curricular nas outras áreas, mormente na Física, para que reconheçam que é tempo de abandonar estratégias antigas, apenas com inegável interesse histórico, e procurar centrar a linguagem da Ciência no conceito de Energia, pois que, para além do que foi referido, como dizia Pagels [31] no seu prefácio ao Código Cósmico, “o mundo visível não e matéria nem espírito, mas a invisível organização da energia"

\section{LEITURA SUPLEMENTAR}

Alegoria de Daniel, o travesso. "A mãe do Daniel ofereceu-lhe 28 blocos indestrutíveis para ele brincar. E, dia após dia, por mais que o Daniel pretendesse esconder alguns dos blo$\cos$, a mãe acabava sempre por descobrir (mesmo sem os observar directamente quando estavam fechados numa caixa ou escondidos na água suja de um tanque), que o número total de blocos era o mesmo. Com o aumento gradual da complexidade das brincadeiras do Daniel (quantas vezes a Natureza também parece brincar!) ia surgindo a necessidade de introduzir termos abstrac- tos de modo a calcular o número total de blocos. Ao fim e ao cabo acabava-se por verificar a seguinte "lei fantástica": a quantidade de blocos mantém-se inalterável independentemente das travessuras do Daniel". (Feynman)

\section{* Universidade do Porto R. de Ceuta $118-6^{\circ}$ andar, sala 44 4000 Porto}

\section{NOTAS}

1 Tal paradigma baseia-se nas ideias de que o conhecimento é construído e é-o a partir das concepções mais ou menos ingénuas e espontâneas dos aprendizes, que deverão, ser o ponto de partida para qualquer estratégia eficaz de ensino-aprendizagem

20 que, mesmo assim, não evitou que Boltzmann se tivesse suicidado!

${ }^{3}$ Um dos seus três artigos de 1905; os outros eram o da Relatividade Restrita e o do Efeito Fotoeléctrico!

${ }^{4}$ Note-se que em Inglaterra já apareceu esta disciplina na parte terminal do curriculum do ensino secundário

5 Note-se que os espaçamentos rotacionais, sendo mínimos, permitem que quase todos os estados quânticos estejam ocupados, enquanto que os vibracionais, intermédios, caracterizam-se pela ocupação não só do estado fundamental como tambem de alguns dos excitados.O espaçamento entre os níveis electrónicos é suficientemente grande para, a temperaturas como as que prevalecem na crosta terrestre, se terem apenas os niveis fundamentais significativamente preenchidos. Assim é que a caracterização destes niveis é geralmente suficiente para os problemas estruturais em Química, só se tendo que recorrer as soluções excitadas para descrições de estados de transição e reaccões fotoquímicas, que de qualquer modo correspondcm já ao segundo nível de discurso químico .

6 Pelo princípio de exclusão de Pauli

7 É nisto que consiste o conhecido princípio de aufbau ou de enchimento

${ }^{8}$ Não confundir com temperatura crítica

${ }^{9}$ Bent propõe $10 \mathrm{~cm}$ para a translação, $3 \times 10^{-7} \mathrm{~cm}$ para a rotação, $3 \times 10^{-9} \mathrm{~cm}$ para a vibração, $10^{-7} \mathrm{~cm}$ para os movimentos electrónicos e $10^{-12} \mathrm{~cm}$ para os nucleares.

${ }^{10}$ Como exemplos temos o $10^{\circ}$ e $11^{\circ}$ anos e as duas partes do $12^{\circ}$ ano

11 Highest occupied molecular orbital e 
lowest unnoccupied molecular orbital, respectivamente: orbital ocupada de maior energia e orbital desocupada de menor energia, cuja importância se refere adiante (3.2)

${ }^{12}$ De choque eficaz se estivermos a trabalhar na Teona das Colisōes

${ }^{13}$ Cineticamente simples, ou num só passo

14 (Na sua forma dinâmica o princípio de exclusão de Pauli, poderá enunciar-se como: mais de dois electrões, como fermiões que são, não podem ter a mesma história.

15 Como se viu, na Mecânica Quântica e na Mecânica Estatística

${ }^{16}$ Artigo de Einstein sobre o Movimento Browniano

17 Realmente a elegante aproximação de Dirac baseia-se nos seus famosos operadores escada que se aplicam não às variáveis mecânicas mas às populações (o que mostra mais uma vez a não separabilidade rigorosa dos aspectos quânticos e estatísticos).

${ }^{18} \mathrm{Um}$ pouco como haviam sido os $\mathrm{n}^{9} \mathrm{~s}$ quânticos no modelo de Bohr.

${ }^{19}$ Embora o físico Pauli tenha sido o primeiro a resolver o átomo de Hidrogénio, dentro da Mecânica das Matrizes.

20 Por cancelamento de erros como Ogilvie insinua?

21 Note-se que, se se considerarem fenómenos como a Radiactividade no âmbito da Química, nem por isso se perde esta unidade estruturante, uma vez que se sabe que a Radiactividade é um fenómeno pelo qual é responsável a forma nuclear fraca e que por outro lado, conforme se disse, se podem unificar os campos electromagnético e o das forças fracas, na chamada força electrofraca.

22 Para a teoria de ligação de valência: electrões de cerne/minimamente alterados relativamente à situação de átomo livre e electrões de valência em dupletos ligantes ou não compartilhados ou ainda excepcionalmente deslocalizados entre estruturas ressonantes

${ }^{23}$ Note-se o que foi dito sobre a maneira de cumprir o segundo princípio para os níveis energéticos electrónicos às temperaturas correntes.

${ }^{24}$ No que toca aos problemas essenciais de estrutura química, conseguem evitar-se as complicaçōes dinâmicas, já que as soluções estacionárias da equação de Schrodinger, caracterizadas por um valor determinado de energia, são inteiramente satisfatórias

${ }^{25}$ Que pela primeira vez introduziu, de uma forma coerente (e em alternativa ao conceito de força) o conceito de energia (Valente e Costa Pereira, 1990)

${ }^{26}$ Conjunto de estruturas ressonantes no caso da teoria de ligação de valência ou os HOMO e LUMO da teoria das orbitais moleculares

${ }^{27}$ Este é um paradigma estocástico (por con- traposição a determinístico) mas em que os fenómenos fundamentais são realmente (e não estatísticamente) aleatórios

${ }^{28} 0$ termo aqui é também usado em contraposição a determinística, mas sendo a origem dessa aleatoriedade estatística.

29 Pode e deve falar-se mesmo numa Termodinâmica Química já que para além de introduzir conceitos novos como potencial quími$\mathrm{co}$, afinidade, fugacidade, refere todas as suas variáveis à unidade de quantidade de substância-a mole, no SI.

30 Veja-se a título de exemplo a correspondência entre os conceitos de temperatura nos dois níveis ilustrada no modelo do sólido de Einstein (Costa Pereira 1990)

31 A aproximação de Lagrange, sendo ainda incoerente dum ponto de vista formal

32 Definido, como é habitual em Física, estipulando unidades e critérios de igualdade e multiplicidade

33 Tantas vezes substantivado, confundido com energia interna, etc .

34 Como é o caso de todas as Ciências quando ultrapassam uma fase incipiente de classificação em que a observação prevalece sobre a experimentação.

35 Como a ideia de impulso, ou a proporcionalidade à velocidade.

\section{BIBLIOGRAFIA}

1. Y. Bertrand, Teorias de Aprendizagem Contemporâneas, Instituto Piaget, 1991.

2. J. K. Gilbert \& D. M. Watts, Concepts, Misconceptions and Alternative Conceptions: Changing Perspectives in Science Education, 10 (1983) 61-98.

3. D. Costa Pereira, The Structural Analysis of Instructions Material Using Diagraph Technique, MSc dissertation, UEA, Norwich, 1977.

4. D. Costa Pereira, Structure of Communication and the Learning of Chemistry, PhD dissertation, UEA, 1979.

5. D. Costa Pereira, C. Alves, L. Lencastre, Jornal de Psicologia, 6,5 (1987) 3-8.

6. J. Ogborn, The Nature of Science and its Implications in Sience For All, Actas do I Encontro sobre Educação em Ciências, 107 124, Braga, 1988.

7. D. Costa Pereira, Impacto das Novas Tecnologias de Informação nas Estratégias de Ensino da Química, Revista Portuguesa de Educação (1991a).

8. R. Harré, As Filosofias da Ciência, Edições $70,1984$.

9. H. A. Bent, The Second Law, and Introduction to Classical and Statistical Thermodynamics, Oxford University Press, 1965.
10. D. Costa Pereira, Boletim da SPQ, 39 (Série II) (1990a) 31-35.

11. M. Ribeiro, D. Costa Pereira, Concepções Erradas sobre Energia, Entropia e Conceitos Afins em Alunos do Ensino Terciário, Revista Portuguesa de Educação, (1989).

12. M. Ribeiro, D. Costa Pereira, R. Maskill International Journal of Science Education, 12, 4 (1990) 391-401.

13. P.N. Johnson, Mental Models, Cambridge University Press, Cambridge, 1983.

14. J. F. Ogilvie, J. Chem. Educ., 67 (1990) 280-292.

15. L. Pauling J. Chem. Educ., 69 (1992) 519-521.

16. R. Tom, Parábolas e Catástrofes, Publicaçōes Dom Quixote, 1985.

17. D. Costa Pereira, Hipermédia no Ensino da Química, Actas do Encontro Computadores no Ensino da Química, Coimbra, 1990b.

18. V. M. S. Gil, Boletim da SPQ, 32/33, II Série (1988) 15-31.

19. D. Costa Pereira, Boletim da SPQ, 46, (Série II) (1991b) 31-35.

20. D. Costa Pereira, Hypermedia and Science Education, - The Case of Chemistry, 5460, in "Hypermedia Courseware: Structures of Communication and Intelligent Help", Nato Advanced Series, Springer Verlag, 1992.

21. R. U. SexI, European Journal of Science Education, Vol. 3, 3 (1981) 285.

22. R. Carnap, Einfuhrung in die Philosophie der Naturwissenschaften, Munich, 1969.

23. F. Bacon, Novum Organum, Londres, 1620.

24. G. Bachelard, Le Nouveau Esprit Scientifique., Paris, 1934.

25. L. Wittgenstein, On Certainty, Blackwell, Oxford, 1969.

26. R. Driver, The Pupil as Scientist, Milton Keynes: Open University, 1983.

27. M. Sequeira, L. Leite, Newton's Third Law: a Study on Secondary School and University Student's Alternative Conceptions. Actas da $13^{\circ}$ Conferência da ATEE, Barcelona, 1988.

28. R. L. Gregory, Mind in Science, A History of Explanations in Psychology and Physics, Weidenfeld and Nicolson, Londres, 1981.

29. M.E.V.M. Santos, Mudança Conceptual na Sala de Aula, Biblioteca do Educador, Livros Horizonte, 1991.

30. A. Giordan, G. Vecchi, Les Origines du Savoir, Delachaux \& Niestlé, Neuchâtel Paris, 1985.

31. H.R. Pagels, O Código Cósmico, A Física Quântica como Linguagem da Natureza. Gradiva, 1982. 